\title{
A Study on Bangladeshi Biscuit Industry: Consumer Perception Towards Packaging
}

\author{
Fabiha Enam $^{1} \quad$ Syed Zarif Samdani ${ }^{2}$ \\ 1.Senior Lecturer of BRAC Business School, BRAC University, Dhaka, Bangladesh \\ 2.Student, BRAC Business School, BRAC University, Dhaka, Bangladesh
}

\begin{abstract}
The aim of this study is to figure out the packaging effects on consumers' perception, which influences the consumers in buying Bangladeshi biscuits. The research is conducted in two phases; primary and secondary. The objective of both of the researches is to find out the buying pattern and consumer preferences for buying biscuits on the basis of packaging. A survey questionnaire was prepared and the number of respondents is 106 . The survey questions contain both close and open ended questions. Primary analysis is collected through structured questionnaires and graphical interpretations are used for analysis functions. The study shows how the packaging of the product helps to build consumer brand image. It shows that the quality of the packaging has a direct effect on the perceived quality of the product. It also helps to promote the product through its packaging. The study emphasizes on consumer perception based on packaging of biscuits made in Bangladesh.
\end{abstract}

Keywords: Packaging, Consumer Perception, Perceived Quality and price, Biscuits etc.

DOI: $10.7176 / \mathrm{EJBM} / 11-30-01$

Publication date:October $31^{\text {st }} 2019$

\section{Introduction}

Biscuits are becoming the snack choice of Bangladeshi consumers, enabling 15\% growth per year. The market for biscuits is now worth Tk5000-6000 crore with large and well-known brands are taking up the major market share. The annual market for branded biscuits is nearly $\mathrm{Tk} 3,000$ crore now. The market was earlier dominated by small bakeries. Demand for biscuits is growing as entrepreneurs have shifted to automation in baking and consumers are looking for a variety of quality foods at low prices. Traditionally the main function of packaging was to protect the goods while transit and handling. Packaging conveys the image that the brand communicates to the buyer. Packaging is the communication medium through which marketers directly communicate with the customers. Procedures, (for example, cleaning, drying, saving) and materials, (for example, glass, metal, paper or paperboard, plastic) utilized to contain, handle, secure, as well as transport an item. Part of packaging is expanding and may incorporate capacities, for example, to pull in consideration, aid advancement, give machine ID (standardized identifications, and so on.), give basic or extra data, and help in usage. Moreover, it is sometimes called "last five seconds of marketing" or "permanent media" or "the last salesman. Packaging helps the customers to feel more valued. Those products which have better packaging are considered to have higher perceptual position in the mind of the customers.

In order to find the answer of the research question both primary and secondary research are done to identify the perception and significance of packaging for Bangladeshi consumers in Biscuit industry. It focuses on how packaging can influence buyer's buying behavior and its effects on brand equity. Both primary and secondary researches were done based on theories based on consumer's behavior. The latter part is the recommendations given by the respondents.

\section{Methodology}

The research for this study has been conducted in two phases; primary and secondary. The secondary research includes books, journals, working paper, newspaper articles etc. The primary research includes web based surveys and in-depth interviews of 106 respondents.

For primary research a questionnaire was prepared covering the key issues of the study such as brand image, influence in purchasing behavior, quality of packaging, perceived price, significance of design, hygiene factors, attitude towards the product etc. The questionnaire mainly used likert scale to conduct the survey with five point scales like Strongly disagree, Disagree, Neutral, Agree and Strongly Agree. Likert Scale is the most commonly used and widely liked by the respondents along with it helps to focus on one particular topic. The questionnaire also contained one open ended question where respondents have the freedom the write down their recommendations on their preferred packaging. All the respondents are Bangladeshi and age group is around 15 to 40 years old.

Data from secondary sources mainly explained the current market trend and biscuit industry of the country. Academic theories were also explained and how it is related with the findings from the primary research also discussed thoroughly. Academic theories like sensation, consumer imagery, Multi attribute attitude model etc have been applied in this study. The recommendation provided by the respondents helped to identify how their attitude 
towards the brand can be changed through alteration in packaging.

\section{Analysis}

The result of the survey is been described and given below through graphical format. From the study, it is shown than Age from 15 to $40+$ years old have participated in the survey whereas $52 \%$ of them were female and rest is male.

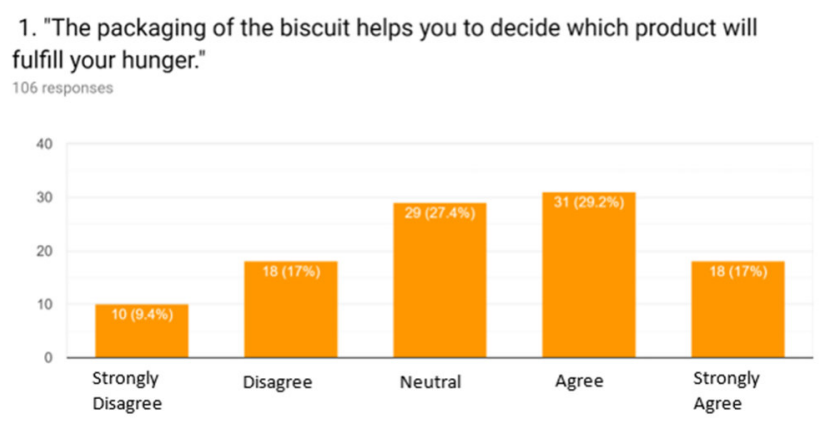

Figure 1. Packaging of biscuits helps you to decide which product will fulfill your hunger The second survey question highlights the strength of brand image.

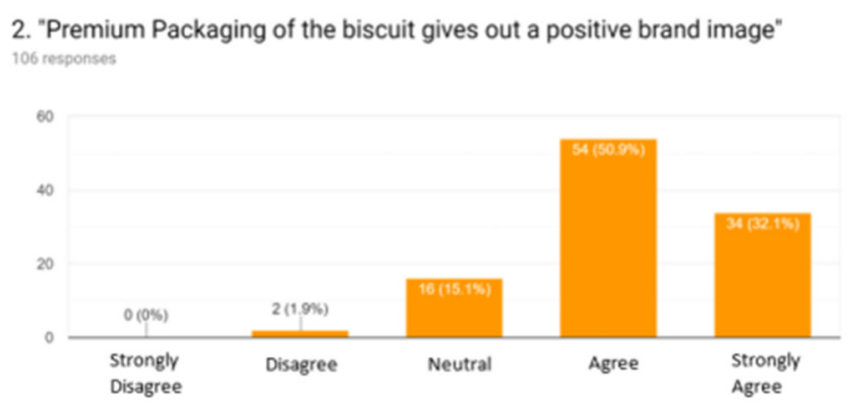

Figure 2. Premium packaging of biscuit gives out a positive brand image

The above result emphasizes how premium packaging has a positive impression on brand equity. Sensation plays an important role here. Respondents perceive that if the packaging is good that brand will be also good.

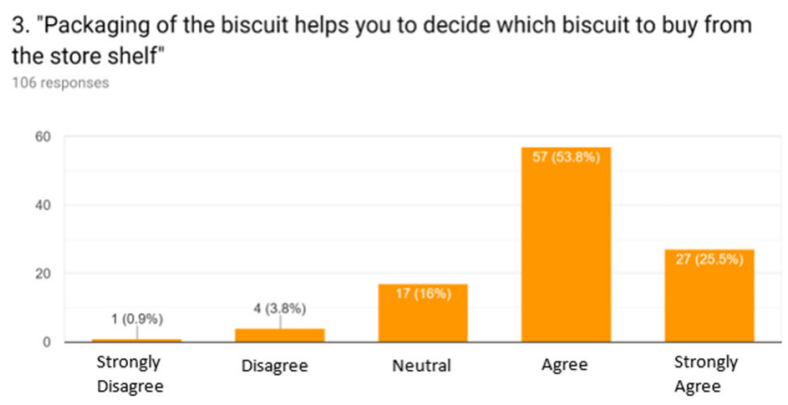

Figure 3. Packaging of the biscuit helps you to decide which biscuit to buy from the store shelf

Good Packaging helps to stand out from its competitors. It helps to attract the variety seeking customers to buy the product. $57 \%$ of the respondents agree that packaging influences their buying behavior.

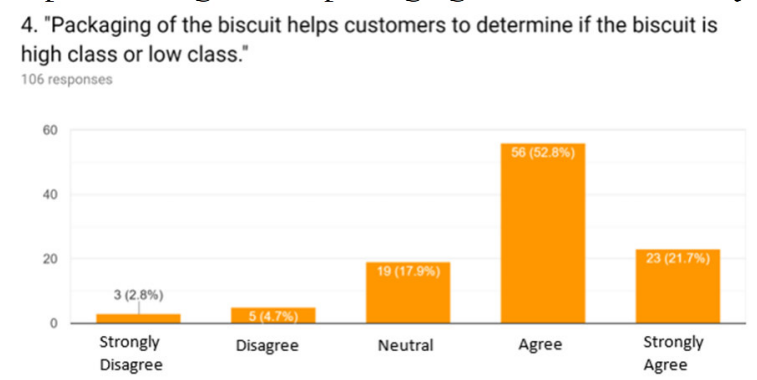

Figure 4. Packaging of the biscuit helps customer to determine if the biscuit is high class or low class The graph shows that packaging is positively correlated with perceived quality of the product. $56 \%$ of the 
respondents agree that packaging creates a perception of the brand. Various stimuli like color, design, materials and ingredients help to create a distinct impression of the brand.

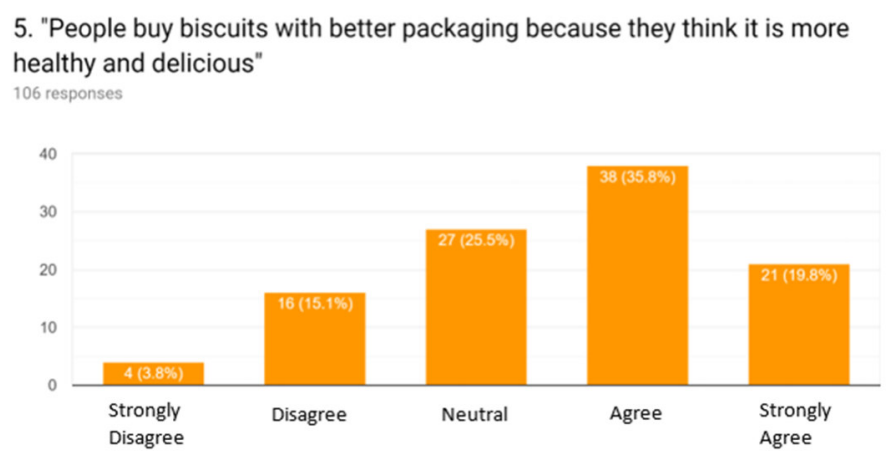

Figure 5. People buy biscuits with better packaging because they think it is more healthy and delicious

The graph proves that better packaging helps to create a positive impression of not only the product but also the organization itself. $38 \%$ of the respondents agree and $21 \%$ respondents strongly agree in response.

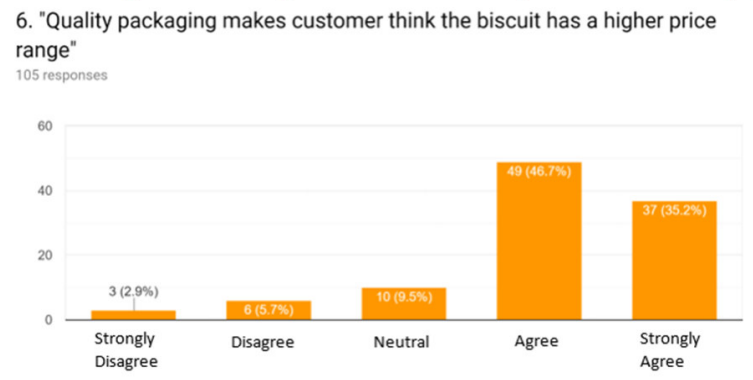

Figure 6. Quality packaging makes customer thing the biscuit has a higher price range

It shows a price/quality relationship. Various stimuli such as quality packaging and design portrays its expected pricing and people made a perception about the price of the product.

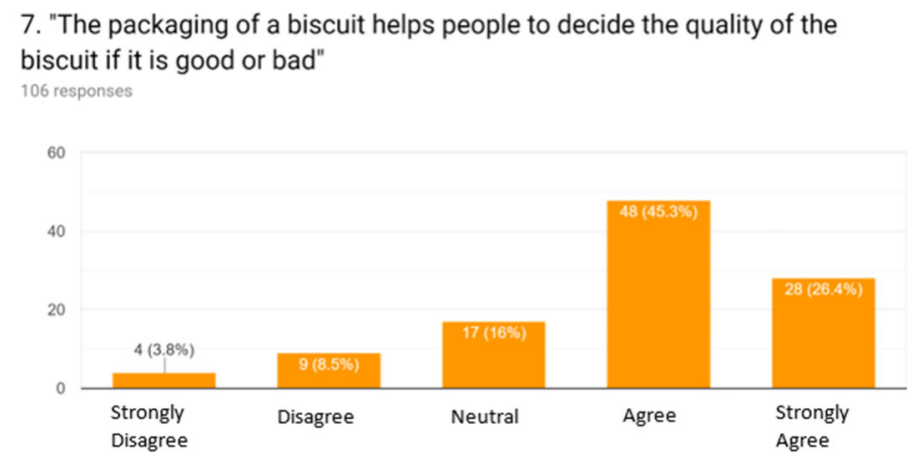

Figure 7. The packaging of a biscuit helps people to decide the quality of the biscuit if it is good or bad

The above question also reflects the perception of the consumers towards its packaging. Most of the respondents agree that packaging has a strong influence on quality of the product.

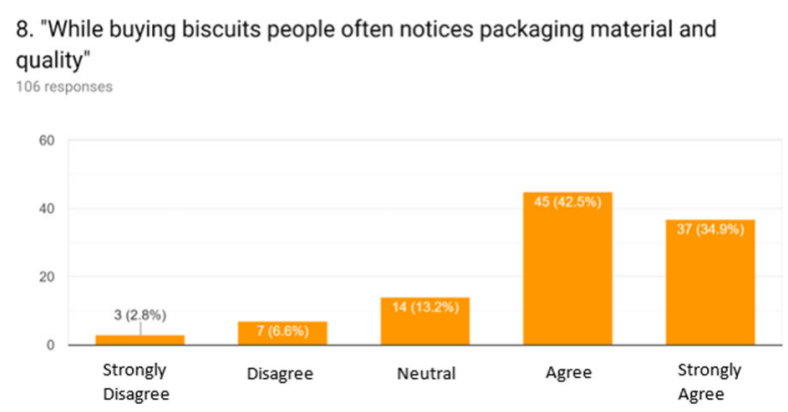

Figure 8 . While buying biscuits people often notices packaging materials and quality

The graph shows that consumers are aware of the packaging materials and quality of the design while buying 
biscuits.

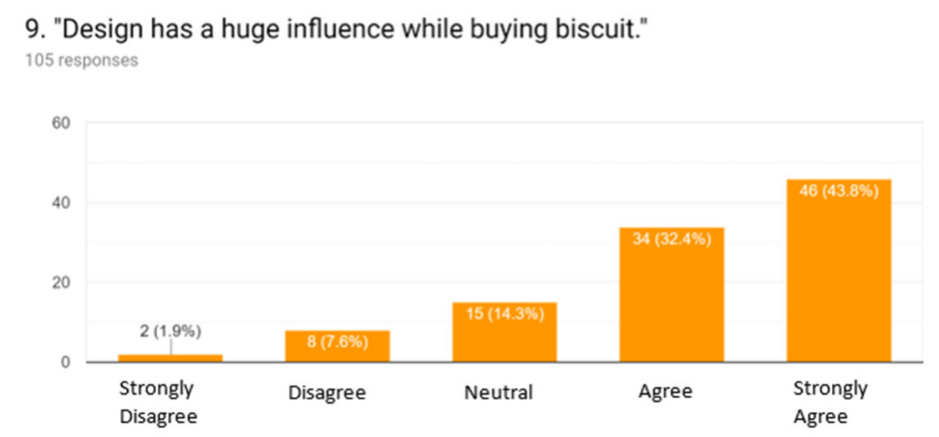

Figure 9. Design has a huge influence while buying biscuit

Visuals play a significant role in buying biscuits as well. $46 \%$ of the respondents strongly agree that design plays a huge influence in buying biscuits.

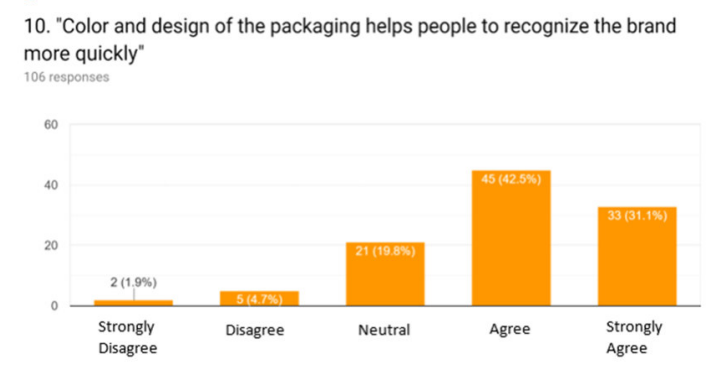

Figure 10. Colour and design of the packaging helps people to recognize the brand more quickly It shows that only packaging help to recall the brand or recognize the brand faster.

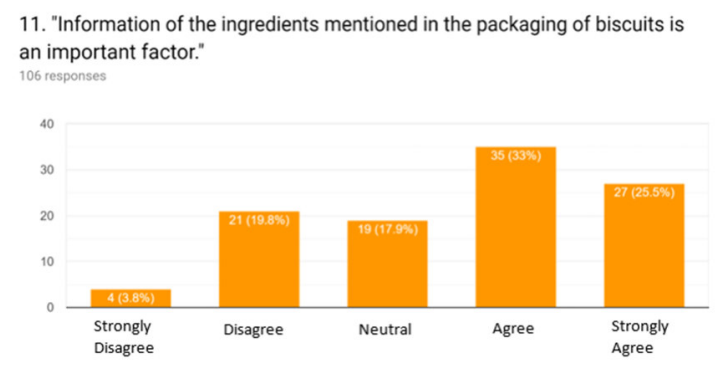

Figure 11. Information of the ingredients mentioned in the packaging of the biscuits is an important factor

The above graph discusses that majority of the respondents agree about the information written on the packaging is an important factor.

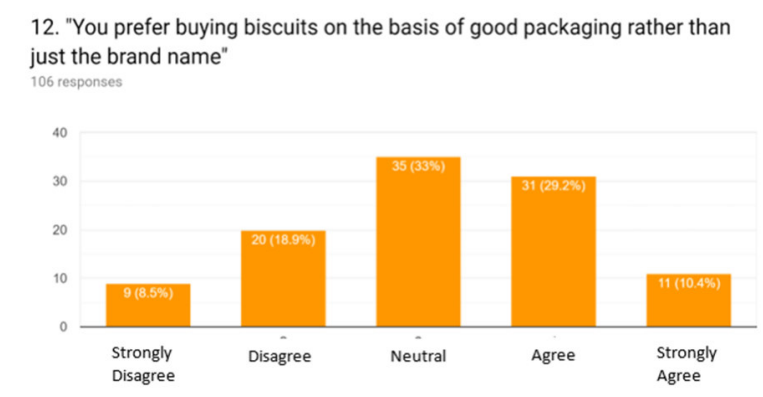

Figure 12. Customer Preference buying biscuit on the basis of good quality packaging rather than just the brand name

This question has mix responses about the basis of the preference of buying biscuits. Out of 106 respondents $31 \%$ agree that packaging is more preferred that brand name while biscuits. On the other hand $35 \%$ neither agree nor disagree about their preferences. $20 \%$ of the respondents disagree about it. 


\section{Discussion}

The questionnaire contains several key issues related with packaging such as quality design, quality materials, information selling, color, brand equity etc. influence in consumer buying behavior. From the response of the survey we came to a conclusion that sensation plays a significant role while choosing the product. Most of the wrappers of the biscuits made in Bangladesh is very colorful so consumer is influenced by its color as well as materials of the packaging. The study also shows that premium packaging has a positive correlation with the brand image as well as pricing. Packaging builds customer image on biscuits. It is directly related with the positioning element of the consumers. There is a significant statistical effect of "the role of packaging in promoting the products" on Jordanian consumer's perception of product quality at the Point of purchase. A study suggested that color and design contrast can attract huge number of consumers. Product quality perception, and also this finding is supported another study who found that there is a strong positive correlation between promotional role of packaging and consumers' attraction to good packaging. The color and the design of the wrapper of biscuit brands in Bangladesh must be of high quality to grab highest consumers. Perceived price and quality is hugely determined through packaging.

\section{Findings \& Recommendation}

The aim of this paper is to identify effects of consumer perception towards packaging. From the above analysis the study has found several major findings. First of all, good packaging caries a positive image of the brand and add value to the brand equity. Secondly, it is also associated with pricing and good quality. People perceive premium packaging as a good quality product as well as expensive. Thirdly, distinct color and premium packaging makes the product stands out from its competitors. In addition, packaging style and quality plays a positive and influential role in consumer buying behavior. Just as packaging quality is important to consumers so is marketing role in packaging information and selling. Package design and materials choices can reflect the brand image. The study shows that people are aware of the information written on a package and they read it before buying the product. Lastly, it is shown that premium packaging is positively correlated with brand equity. If the brand is good, then consumer expects the packaging would also be good.

Majority of the recommendations are suggested by the respondents. Many respondents suggested the packaging should be more environmental friendly and it could be recycled. Few respondents recommended about using zip bag as a package so the biscuits should be easy to keep and the biscuits will be fresh. Different sizes of packaging of biscuits are highly recommended. Most of the packages of our biscuit companies are family size. Different sizes such as pocket size should be introduced more widely.

\section{Limitation}

The research supports that packaging perception influence the buying behavior of the consumers. The major limitation is the whole study is conducted within a period of 3 weeks. Along with the number of respondents are only 106 who are mostly urban dwellers. So the outcome can be considered is a bit biased. The biscuit industry in Bangladesh is expanding very quickly but yet there is not much research about it. So a large number of areas are still unexplored, further research about the various aspects of this industry will really help the industry to bring more quality products.

\section{References}

A Cross Cultural Study, Journal of Applied Packaging Research, pp. 61-94, 2015.

C .Lal, F. Yambrach, L. McProud, "Consumer Perceptions Towards Package Designs:

G.M.Abdalkrim, R.S.AL-Hreza, "The Role of Packaging in Consumer's Perception of Product Quality at the Point of Purchase", European Journal of Business and Management, Vol. 5, no.4, pp. 69-82, 2013.

J. Zakeri,V.V. Hasani, "THE ROLE AND IMPACT OF THE PACKAGING EFFECT ON CONSUMER BUYING BEHAVIOUR”, Eco forum, vol. 4, iss. 1, pp. 232-40, 2015.

K. Chind. (2012), "Purchasers' Perception on Packaging Formal Design: A Comparative Case Study on Luxury Goods Merchandizing", Procedia - Social and Behavioral Sciences, Vol. 42, pp. 436-442.

L. Chandra. (2015), "Consumer Perceptions Towards Package Designs: A Cross Cultural Study", Journal of Applied Packaging Research, Vol. 7, No.2, pp. 61-94.

O.A.N. Vila, "Consumer Perceptions of Product Packaging", Journal of Consumer Marketing, Vol. 23 Iss. 2 , pp. 100-112, 2006

Silayoi, P. and Speece, M. (2004), "Packaging and purchase decisions: a focus group study on the impact of involvement level and time pressure”, British Food Journal, Vol. 106, No. 8, pp. 607-28. 